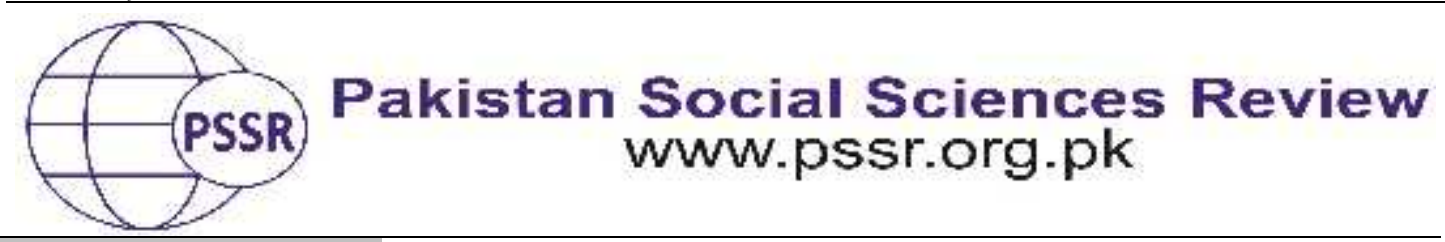

RESEARCH PAPER

\title{
Mental Health and Positive Impact of Man Made Disasters and Natural Disasters in Pakistan: A Comparative Study
}

\author{
Samra Zubair Lodhi*1 ${ }^{*}$ Dr. Seema Gul ${ }^{2}$
}

1. Ph. D Scholar, Department of Psychology, Female Campus, International Islamic University, Islamabad, Pakistan

2. Assistant Professor, Department of Psychology, International Islamic University, Islamabad, Pakistan

\begin{tabular}{|c|c|}
\hline PAPER INFO & ABSTRACT \\
\hline $\begin{array}{l}\text { Received: } \\
\text { March 06, } 2021 \\
\text { Accepted: } \\
\text { June 05, } 2021 \\
\text { Online: } \\
\text { June 10, } 2021\end{array}$ & $\begin{array}{l}\text { Trauma leaves impact on mental health of victims as well as } \\
\text { survivors. The objective of present study is to find the level of } \\
\text { posttraumatic growth in the victims of man-made disaster and } \\
\text { natural disaster in Pakistan which refers to mental health. The } \\
\text { total sample size was } N=600 \text { which comprised of } n=300 \text { victims }\end{array}$ \\
\hline $\begin{array}{l}\text { Keywords: } \\
\text { Post Traumatic } \\
\text { Growth, Man- } \\
\text { Made Disaster, } \\
\text { Natural Disaster, } \\
\text { Mental Health }\end{array}$ & $\begin{array}{l}\text { of man-made disaster (Abused }=150 \text { i.e } 75 \text { males } \& 75 \text { females } \\
\text { and Bomb Blast victims i.e } 75 \text { males \& } 75 \text { females). Same as } 300 \\
\text { victims of natural disaster (earthquake victims } 150 \text { i.e } 75 \text { males } \\
\& 75 \text { females and flood victims }=150 \text { i.e } 75 \text { males \& } 75 \text { females). } \\
\text { Purposive sampling technique was used to collect data. Urdu } \\
\text { translated version of PTGI is used for data collection that was }\end{array}$ \\
\hline $\begin{array}{l}\text { *Corresponding } \\
\text { Author }\end{array}$ & $\begin{array}{l}\text { devised by Tedeschi \& Calhoun. It was hypothesized that Post } \\
\text { traumatic growth will be high in the victims of natural disaster } \\
\text { as compared to man-made disaster. It was found that the level } \\
\text { of PTG is a greater in the victims of natural disaster as } \\
\text { compared to man-made disaster. And PTG is found more in the } \\
\text { males than females, while in subscales the significant difference } \\
\text { is found on 'spiritual change' between these two groups } \\
\text { Moreover Level of PTG increases with passage of Time. }\end{array}$ \\
\hline
\end{tabular}

\section{Introduction}

Tedeschi and Calhoun define the PTG as "positive psychological change experienced as a result of struggles with highly challenging life circumstances" (Tedeschi\& Calhoun, 2004). The PTG is currently being studied in trauma sufferers all over the world due to the positive aspect of trauma on any trauma victims is getting attention. There are many studies which have assessed this phenomenon in different types of disasters individually. e.g, studies on post traumatic growth in the victims of earthquake (Haung, Wong, Tan, 2014), flood, fire disasters (Leykin, Lahad, Bonneh, 2013), hurricanes, Tsunami survivors (Augustin, 2014, Kaur, 2009), mount eruptions (Subandi, et. al., 2010), war, bomb blasts, terrorism and abuse (Yih-Hsing Liu, 2012), accidents ( Blore, Farrell, \& Clifford,2008). 


\section{Literature Review}

\section{PTG and Man-made Disaster/ Natural Disasters}

Linley and Joseph (2004) conducted a review of 39 studies and indicated that positive change is reported in approximately $30-70 \%$ of survivors of different traumatic experiences. Some of these events include plane crashes, car accidents, hurricanes, earthquakes, combat, child abuse, cancer, heart attack, HIV/AIDS, and other life experiences such as parental divorce, bereavement and immigration.

Moreover Siegrist \& Sutterlin (2014) approved that man-made disasters are more severe in its physical and psychological effects as compared to natural disaster. It was based upon studies typically contrasted scenarios in which different groups of participants rated the severity and impact of disasters that were equated for their death toll or other damage, but differed in whether they were caused by natural or human factors. For example, one study compared ratings for a chemical plant explosion that released sulpher dioxide and killed 15 people in a neighboring town to a volcano that released sulpher dioxide and killed 15 people in a neighboring town. Participants felt the plant explosion was more severe than the volcano. A similar result was obtained for a forest fire that was caused either by a lightning strike or by a fire someone lit that burned out of control.

\section{PTG and Terrorism}

In a 2004 United Nations Security Council conference, terrorism was defined as:"any action that is intended to cause death or serious bodily harm to civilians or non-combatants, when the purpose of such an act...is to intimidate the population, or to compel a government or an international organization to do or to abstain from doing any act" (A More Secure, 2004, pg. 65).

A review of the research on PTG and terrorism indicates that some of the earlier studies began soon after the September 11th, 2001 terror attack in the US. The attack shook Americans, as well as others affected by it, and challenged them to create a new sense of 'normal', 'safety', and of 'self' while learning to live with the trauma of the attack.

However, in addition to reported high levels of distress following the attack, national polls reported that Americans experienced a variety of positive outcomes from dealing with the attacks, such as re-examining their life priorities and feeling closer to their families (Danieli et al., 2005). The September 11th attack also created an unprecedented surge of interest in the fields of trauma and terrorism, and numerous researchers, particularly in the field of psychology, began conducting empirical studies on various aspects of the attack.

Research focusing on both indirect and direct exposure to terrorist attacks in Western contexts has largely shown evidence of PTG. For instance Linley, Joseph, 
Cooper, Harris and Meyer (2003) found evidence of PTG in British citizens who were vicariously exposed to the September 11th attacks through television viewing. Limited research has also indicated a weak relationship between PTG and terrorism (Laufer\& Solomon, 2006). For example, Milam, Ritt-Olson, Tan, Unger and Nezami (2005) conducted a study among an ethnically-diverse American adolescent sample indirectly exposed to the September 11th terrorist attacks. The findings showed that the majority of the sample showed neutral-mild levels of PTG. The authors noted that the ethnic diversity might have explained this, as a large number of IranianAmerican participants reported neutral PTG scores, since the larger, negative implications from the terrorist attacks for these participants would have been greater than for other ethnic groups.

Interestingly, it also appears that individuals can experience both positive and negative changes following terrorism exposure. For example, a study by Blix et al. (2013) conducted in Oslo after the 2011 bomb attack, examined perceived PTG among 197 employees of the ministry who were at work during the attack. The results showed that while perceived PTG was significantly related to higher levels of life satisfaction, it also showed that PTG was associated with elevated levels of posttraumatic stress (Kiran, Rana, \&Azhar, 2010).

\section{PTG and Abuse}

Tylor, Wood, and Lichtman's (1983) research on survivors of life threatening attacks, illness and natural disasters concluded that not only did the majority of those so exposed overcome the victimizing aspects of the experience, many actually benefited from it.

Individuals exposed to interpersonal or relational trauma such as bullying, physical assault, sexual assault, and intimate partner violence generally report greater symptom severity in contrast to those who experience other forms of trauma such as motor vehicle accidents (Breslau, 2009; Lancaster, Melka, \& Rodriguez, 2009; Shakespeare-Finch \& Armstrong, 2010).Exposure to traumatic events is associated with a range of psychological consequences, such as anxiety, depression (Breslau, Davis, Andreski, \& Peterson, 1991; Briere, 2004; Kessler, Sonnega, Bromet, \& Hughes, 1995) as well as interpersonal dysfunction and risky sexual behavior (Ouimette\& Brown, 2003; Polusny \& Follette, 1995).

Several factors are suggested to promote PTG after stressful events, including type of trauma, in addition to younger age and female gender. Although conflicting findings exist, studies suggest that there may be less growth associated with personal traumas (i.e., physical or sexual assault, accidents) and more growth associated with shared traumas (i.e., disasters, loss). It was examined whether certain types of war-related traumas are associated with more PTG in a sample of 203 Iraqi students living in Turkey who had experienced severe war-related traumatic events. It was found that adversity-type events positively predicted growth, whereas trauma to self predicted growth negatively. Males and females 
showed a different pattern of relationship with growth. Correlations of growth with younger age and adversity observed in females were not seen in males. In addition, different trauma types may lead to differing levels of growth, and this difference may be more pronounced when gender is taken into account (Kilic, Magruder, Koryurek, 2015).

\section{PTG and Natural Disasters}

Post traumatic positive changes tend to be observed in several key areas: people may report a greater sense of their personal strength; they may discover a different perspective on their relationships; they may experience a changed philosophy of life, such as a greater appreciation for life and its new possibilities, modified priorities, or a shift in their value systems; and they may describe spiritual growth (Calhoun \& Tedeschi, 2006; Kilmer, 2006)

It was found while Kilmer \& Gil -Rivas (2008) conducted a study on the victims of natural disaster. It was also found in the parents who suffered from natural disaster grew psychologically afterwards (Siqveland, Hafstad, \&Tedeschi, 2012), in flood victims the psychological distress and PTG are marginally correlated (Aslam \& Kamal, 2015). While a qualitative study conducted on PTG among individuals exposed to flood in Pakistan by Aslam (2010) and found that positive changes were reported to occur in five domains of an individual life including, recognizing new possibilities, perceiving personal strength, increasing spiritual sense, improving relationship, and appreciation of life. Moreover social support had significant direct association with PTG but not with PTSD and a positive indirect prediction on PTG through cognitive reappraisal while assessing the PTG among adolescent survivors of the Wenchuan earthquake (Zhou, Wu, Fu, \& An, 2015).

The six months later study after the Ya'an earthquake PTG found in the survivors. And found that Social support had significant direct association with PTG, and social support had a positive indirect prediction on PTG through cognitive reappraisal (Zhou, $\mathrm{Wu}, \&$ Zhen, 2017). PTG can also occur from challenges to values and beliefs that arise from vicarious exposure to threatening events (Linely, Joseph, Cooper, Harris, \& Myer 2003).

\section{Hypotheses}

i. Post traumatic growth will be high in the victims of natural disaster as compared to man-made disaster.

ii. There will be gender difference in the level of post traumatic growth in the victims of natural and man-made disaster.

iii. There will be difference in the level of Post traumatic growth among the victims of man-made disaster and natural disaster regarding Level of Education. 
iv. There will be difference in the level of post traumatic growth in relation to types of abuse.

v. There will be difference in the victims of man-made disaster and natural disaster regarding Time ('passed after traumatic event)

vi. There will be difference in level of post traumatic growth in relation to marital status.

\section{Material and Methods}

\section{Sample}

The level of posttraumatic growth was determined for the current phase of the study on trauma victims $(\mathrm{N}=600)$ who had suffered man-made $(n=300)$ or natural disaster $(n=300)$ with the range 20 to 40 years through snowball purposive sampling. Snowball sampling technique is non probability technique where existing study participants recruit future research participants from among their acquaintances. Thus the sample group is said to grow like a rolling snowball. As the sample builds up, enough data are gathered to be useful for research (Creswell, 2003). The victims of Man-made disaster were those who went through either Bomb Blast $(n=150$, comprising of $n=75$ Males and $n=75$ females) or Abuse $(n=150$, comprising of $n=75$ Males and $n=75$ females). On the other hand the victims of Natural disaster were those who went through either Earthquake $(n=150$, comprising of $n=75$ Males and $n=75$ females) or Flood ( $n=150$, comprising of $n=75$ Males and $n=75$ females). Victims of disasters were taken after consent and who were reported and identified by different Rehabilitation Centers, Non-governmental organizations working for management and rehabilitation of the victims of disaster; rescue departments, and Police Department. Those victims were included in the present study who have faced earth quake, flood, bomb blast or abuse before 6 months at least because the time duration of bereavement or overcoming the grief period is at least six months (DSM V, 2013).

\section{Operational Definition}

\section{Man-Made Disaster}

A disastrous event caused directly and principally by one or more identifiable deliberate or negligent human actions. It is also called human-made disaster. Technological or man-made hazards (complex emergencies/ conflicts, famine, displaced populations, industrial accidents and transport accidents, terrorist attacks e.g Bomb Blasts and Abuse) are events that are caused by humans and occur in or close to human settlements (IFRC, 2017). In present study, the victims of Bomb Blast and Abuse are considered under this category. Because Pakistan has been hugely struck with massive bomb explosions resulting in multiple casualties in the past few years. the recorded numbers of terrorist incidents in 
Pakistan has increased approximately 1400\% from 168 per year in 1980 to over 5,400 per year today with a current total death toll of 29,680. According to Global Terrorism Database (GTD) during 1970s, only 17 terrorist incidents took place in Pakistan. Whereas the average terrorist incidents per year from 1980-1990 were 24, from 1991-2000 were 155, and from 2001-2010 were 249 in number (Shabib, Luqman, \& Roger, 2015). According to the Annual Report (2018) of Human Rights Commission (HRCP) 4,131 casualties were reported in abuse cases in 2017, including 2,057 deaths and 2,074 injuries. Considering gradually increasing and alarming statistics the sample of abuse is taken for the current study.

\section{Natural Disaster}

Natural disaster is defined as

"The consequences of events triggered by natural hazards that overwhelm local resp onse capacity and seriously affect the social and economic development of aregion" (Inter-Agency Standing Committee, 2006).

Natural hazards are naturally occurring physical phenomena caused either by rapid or slow onset events which can be geophysical (earthquakes, landslides, tsunamis and volcanic activity), hydrological (avalanches and floods). In present study, the victims of flood and earthquake are considered under this category. Because flood and earthquake are most prevalent types of natural disaster in Pakistan according to the statistics given by International disaster database i.e, EMEDAT (2012).

\section{Post Traumatic Growth}

It refers to positive psychological change experienced as a result of the struggle with highly challenging life circumstances (Calhoun \&Tedeschi, 1999, 2001). In the current study high scores on the post traumatic growth inventory (PTGI) means high level of post traumatic growth in the individual.

\section{Instrument}

\section{Post traumatic growth inventory (PTGI)}

In present study the Urdu version of PTGI was used that was translated by Saghir and Kousar in 2007 (Annexure A).It was originally developed by Tedeschi and Calhoun in 1996, based on a review of the available literature on responses to trauma, interviews with persons dealing with a variety of major crises or stressors (e.g., becoming physically handicapped as adults, death of a child), and the final items of the 21-item scale were subjected to a variety of evaluations of its validity, reliability, and factor structure (Taku, Cann, Calhoun, \&Tedeschi, 2008).

PTGI contains five factors i.e, Relating to Others, New Possibilities, Personal Strength, Spiritual Change, and Appreciation of Life. Factor I (item \# 
$6,8,9,15,16,30,21$ with variance $17 \%$ and Test retest reliability $a=0.85$ ), Factor II (item \# 3,7,11,14,17 with variance $16 \%$ and Test retest reliability $a=0.84)$, Factor III (4, $10,12,19$ with variance $11 \%$ and Test retest reliability a=0.72), Factor IV (5,18 with variance $9 \%$ and Test retest reliability a $=0.85)$, Factor VI $(1,2,13$ with variance $9 \%$ and Test retest reliability a $=0.67$. (Annexure $\mathrm{A}$ )

\section{Procedure}

For first part of the study, Urdu version of PTGI (translated by Saghir \& Kousar, 2007) was taken from University of the Punjab, Lahore through proper procedure. Then four types of trauma victims were approached for data collection including victims of flood, earthquake (natural disasters), abuse and bomb blasts (man-made disaster). The victims of natural disaster i.e flood and earthquake were taken from different areas of Rawalpindi. Data was collected door to door. Whereas the victims of abuse was selected from shelter homes and Dar-ul-Aman of Rawalpindi. The abused males were approached through Police Department. The victims of Bomb Blast were taken from population around Imam Bargah's and Mandi's of fruits and vegetables because these areas were having the history of Bomb Blasts.

Then the proper written consent from sample was taken. After taking the consent, they were briefed about the nature of study. They were assured that the information will be kept confidential and would only be used for research purpose only. The instrument i.e, PTGI was (Urdu Version) administered on individual bases. Then the scores were fed into computer for statistical analysis for which statistical package for social sciences (SPSS version 22, Windows 8) was used.

\section{Results and Discussion}

Table 1

Mean differences between man-made and natural disaster for the whole sample on the score of PTGI and on its subscales $(N=600)$.

\begin{tabular}{|c|c|c|c|c|c|c|c|c|c|}
\hline & \multicolumn{2}{|c|}{$\begin{array}{c}\text { Man-Made } \\
\text { Disaster }(n=300)\end{array}$} & \multicolumn{2}{|c|}{$\begin{array}{c}\text { Natural Disaster } \\
(n=300)\end{array}$} & \multirow[b]{2}{*}{$\mathrm{t}(598)$} & \multirow[b]{2}{*}{$\mathrm{P}$} & \multicolumn{2}{|c|}{$95 \%$ CI } & \multirow[t]{2}{*}{ Cohens'd } \\
\hline & $\mathrm{M}$ & SD & $\mathrm{M}$ & SD & & & LL & UL & \\
\hline PTGI & 78.99 & 11.34 & 82.23 & 12.65 & -3.30 & .001 & -5.16 & -1.31 & 0.270 \\
\hline RTO & 25.38 & 5.22 & 27.08 & 4.97 & -4.08 & .000 & -2.51 & -0.88 & 0.334 \\
\hline $\mathrm{NP}$ & 19.22 & 3.28 & 19.52 & 3.63 & -1.06 & .288 & -0.85 & 0.25 & 0.087 \\
\hline PS & 15.99 & 2.76 & 16.05 & 2.95 & -0.27 & .786 & -0.52 & 0.39 & 0.021 \\
\hline SC & 6.19 & 2.47 & 7.36 & 1.86 & -6.56 & .000 & -1.52 & -0.82 & 0.536 \\
\hline AOL & 12.21 & 1.93 & 12.22 & 2.06 & -.041 & .967 & -0.33 & 0.31 & 0.005 \\
\hline
\end{tabular}

Note: $M=$ Mean; $S D=$ Standard Deviation; PTGI=Posttraumatic Growth Inventory; RTO=Relating to Others; NP=New Possibilities; PS=Personal Strength; $S C=$ Spiritual Change; $\mathrm{AOL}=$ Appreciation of Life

Table 1 shows the mean differences and standard deviation between manmade and natural disaster on the score of PTGI and its subscales. Independent- 
samples t-test indicates that there are highly significant means differences between man-made and natural disaster on PTGI and its subscales RTO and spiritual change (SC). Figures show that victims of natural disaster have higher mean on PTGI, RTO and SC. Whereas on all other subscales mean differences between man-made and natural disaster are non-significant, however trend show that natural disaster sample have slightly higher mean but this mean difference is not statistically significant.

Table 2

Mean differences between married and unmarried on the score of PTGI $(\mathrm{N}=596)$

\begin{tabular}{cccccccccc}
\hline & \multicolumn{2}{c}{$\begin{array}{c}\text { Married } \\
(\mathrm{n}=464)\end{array}$} & \multicolumn{2}{c}{$\begin{array}{c}\text { Unmarried } \\
(\mathrm{n}=132)\end{array}$} & & & \multicolumn{2}{c}{$95 \% \mathrm{CI}$} & Cohens'd \\
\hline & $\mathrm{M}$ & $\mathrm{SD}$ & $\mathrm{M}$ & $\mathrm{SD}$ & $\mathrm{t}(594)$ & $\mathrm{P}$ & $\mathrm{LL}$ & $\mathrm{UL}$ & \\
\hline PTGI & 80.8 & 12.38 & 80.04 & 11.27 & 0.64 & .52 & -1.58 & 3.11 & 0.063 \\
\hline
\end{tabular}

Note: $M=$ Mean; $S D=$ Standard Deviation; PTGI=Posttraumatic Growth Inventory

Table 2 shows the mean differences and standard deviation between married and unmarried sample on the score of PTGI. Independent-samples t-test indicates that there are no statistically significant means differences between married and unmarried sample. Both groups have approximately same score on PTGI.

Table 3

Chi-Square test and descriptive statistics for Man-made and Natural disaster by Education Level $(\mathrm{N}=600)$

\begin{tabular}{cccc}
\hline Education Level & $\begin{array}{c}\text { Man-Made Disaster } \\
(\mathrm{N}=300)(\%)\end{array}$ & $\begin{array}{c}\text { Natural Disaster } \\
(\mathrm{N}=300) \\
(\%)\end{array}$ & $\begin{array}{c}\text { Total } \\
(\mathrm{N}=600) \\
(\%)\end{array}$ \\
\hline Illiterate & $46(15.3)$ & $60(20.0)$ & $106(17.7)$ \\
\hline Primary & $54(18.0)$ & $49(16.3)$ & $103(17.2)$ \\
\hline Middle & $47(15.7)$ & $74(24.7)$ & $121(20.2)$ \\
\hline Matric & $68(22.7)$ & $69(23.0)$ & $137(22.8)$ \\
\hline Intermediate & $28(9.3)$ & $30(10.0)$ & $58(9.7)$ \\
\hline Graduation & $29(9.7)$ & $11(3.7)$ & $40(6.7)$ \\
\hline Master & $28(9.3)$ & $7(2.3)$ & $35(5.8)$ \\
\hline
\end{tabular}

Note: $\chi^{2}=28.89 \mathrm{df}=6, \mathrm{p}<.001 ;$ Numbers in parentheses indicate column percentages.

${ }^{*} \mathrm{p}<.05$

Table 3 indicates the frequency difference between education level and type of disaster man-made and natural. Chi-square results show a statically significant frequency difference in education level between man-made and natural disaster. $\left(\chi^{2}=\right.$ $28.89, p<.001)$. Less educated more likely to support natural disaster and educated respondents are more likely support to man-made disaster 
Table 4

Chi-Square test and descriptive statistics for Man-made and Natural disaster by Time Passed after disaster faced $(\mathrm{N}=600)$

\begin{tabular}{lccc}
\hline \multicolumn{1}{c}{ Time Duration } & $\begin{array}{c}\text { Man-Made Disaster } \\
(\mathrm{N}=300)(\%)\end{array}$ & $\begin{array}{c}\text { Natural Disaster } \\
(\mathrm{N}=300)(\%)\end{array}$ & $\begin{array}{c}\text { Total } \\
(\mathrm{N}=600)(\%)\end{array}$ \\
\hline Less than 3 Years & $118(39.3)$ & $35(11.7)$ & $153(25.5)$ \\
\hline 3 - 5 Years & $26(8.7)$ & $170(56.7)$ & $196(32.7)$ \\
\hline $5-10$ Years & $68(22.7)$ & $38(12.7)$ & $106(17.7)$ \\
\hline $10-15$ Years & $88(29.3)$ & $57(9.5)$ & $145(24.2)$ \\
\hline $\begin{array}{l}\text { Note }: \chi^{2}=165.94 \mathrm{df} \\
\text { percentages. }\end{array}$ & $3, \mathrm{p}<.001 ;$ Numbers & in parentheses indicate column \\
${ }^{*} \mathrm{p}<.05$
\end{tabular}

Table 4 indicates the frequency difference between time passed after disaster faced the disaster and type of disaster man-made and natural. Chi-square results show a statically significant frequency difference in time passed after disaster faced the disaster between man-made and natural disaster. $\left(\chi^{2}=165.94, p<.001\right)$.

Table 5

Mean Differences among types of abuse on PTGI scores $(\mathbf{N}=190)$

\begin{tabular}{cccc}
\hline Types of Abuse & $\mathrm{N}$ & Mean & Std. Dev \\
\hline Physical Abuse & 64 & 77.58 & 9.70 \\
\hline Psychological Abuse & 28 & 78.25 & 9.88 \\
\hline Emotional Abuse & 29 & 77.14 & 11.29 \\
\hline Financial Abuse & 21 & 77.38 & 11.49 \\
\hline Multiple Abuses & 48 & 73.13 & 12.87 \\
\hline
\end{tabular}

$\mathrm{F}(4,185)=1.51, \mathrm{p}>.05$

Table 5 represents mean, standard deviation, along with F value on PTGI scores among types of abuse. There is non-significant mean differences among types of abuse on PTGI scores. The means among types of abuse are approximately equal except multiple abuses.

\section{Discussion}

The present study was aimed to find out the comparison of PTG level in the victims of man-made disaster and natural disaster. It is found that level of PTG is higher in the victims of natural disaster on PTGI as compared to the victims of Man Made disaster. Previous literature shows that adults victims exposed to natural disaster adapt better than those exposed to man-made disaster and females adapt to man-made disasters better than men (Riaz, Malik, \& Nawaz, 2015). Furthermore people are generally more angry and frustrated by disasters that that are caused by people than for disasters that are natural. As a result, they predicted that people would also find human-caused disasters to be more severe than natural 
disasters (Siegrist \& Sutterlin, 2014). In addition a study reports that victims of a tornado had the highest rates of perceived benefit, followed by victims of a mass killing and plane crash (McMillen, Smith \& Fisher 1997; Dannefer\& Philipson, 2010). But there is lack of comparative studies on posttraumatic growth in the victims of man-made and natural disasters at a time. But the current study is an effort to fill this gap of knowledge in previous literature.

It was hypothesized that there is no gender difference in the level of post traumatic growth in the victims of natural and man-made disaster. Results show that male sample has higher mean on PTGI and on its subscale because there is highly significant mean difference between male and female on the score of PTGI and all its subscales on the sample affected in blast, earthquake and flood. Moreover it is evident that score of PTGI and its all subscales male sample has significantly higher mean as compared to female sample. While on the subscale Spiritual Change of male sample affected in flood has higher mean as compared to female but this mean difference is not statistically significant. Contrary to it, there is no significant difference between male and female affected by abuse on PTGI. While on its subscales, spiritual change and appreciation of females have higher scores than males. According to the previous literature it was found that females psychologically grow more to man-made disasters better than men (Riaz, Malik \& Nawaz, 2015; Fisher, 2006). Some of recent studies also found that PTG is high in males as compared to females (Yi ,Zebrack, Kim and Cousino, 2015).

It was hypothesized that there is no difference in level of post traumatic growth in relation to marital status. The mean differences and standard deviation between married and unmarried sample on the score of PTGI. Independent-samples $\mathrm{t}$-test indicates that there is no statistically significant means differences between married and unmarried sample. Both groups have approximately same score on PTGI. The results of present study are in line with previous literature as PTG was significantly. Similarly, Helgeson et al. (2006) reported a very small effect size for the association between marital status and PTG following health-related or personal trauma. One of the most important studies in this field, conducted by Mosher, Danoff-Burg, and Brunker (2006), evaluates the predictors of PTG in adult daughters of patients with breast cancer, such as coping strategies and caregiving. In this research, personal characteristics (age, income, education, marital status, optimism) were not correlated with PTG. Same as PTG was not significantly related to age, and marital status in the study conducted by Teixeira \& Pereira in 2013. In short, in accordance with existing literature on PTG and marital status (Devine, Reed-Knight, Loiselle, Fenton, \& Blount, 2010; Morrill et al., 2008; Mosher et al., 2006; Stanton, Bower, \& Low, 2006; Widows et al., 2005) did not emerge as significant predictors of increased PTG trauma victims.

Another hypothesis was that there is no difference in the level of Post traumatic growth among the victims of man-made disaster and natural disaster regarding Level of Education.Itindicates the frequency difference between education level and type of disaster man-made and natural. Chi-square results show a 
statically significant frequency difference in education level between man-made and natural disaster. $\left(\chi^{2}=28.89, p<.001\right)$. Less educated more likely to support natural disaster and educated respondents are more likely support to man-made disaster same as Kotin (2018) reported that the level of education is positively related to PTG i.e, more education have high level of education in other words. In short previous literature supports the findings of present study as there is a positive relationship between education level and posttraumatic growth (Bellizzi and Blank, 2006; Bower et al., 2005; Cordova et al., 2007; Koutrouli et al., 2012; Kucukkaya, 2010; Sears et al., 2003 \&Wang et, al., 2014).

Another hypothesis was that there is no difference in the victims of manmade disaster and natural disaster regarding Time ('passed after traumatic event). The results of present study indicates a statically significant frequency difference in time passed after disaster faced the disaster between man-made and natural disaster. $\left(x^{2}=165.94, p<.001\right)$. The longitudinal studies they reviewed suggest that PTG develops over time, with most occurring between two weeks and two months. Predictors of enduring growth include self efficacy and positive affect. The level of social support at 12 and 18 months following the earthquake predicted subsequent PTG (Jia, Liu,Ying\& Lin, 2017; Konvisser, 2013; McCormack \& McKellar, 2015).

It was also hypothesized that there is no difference in the level of post traumatic growth in relation to types of abuse. There is non-significant mean differences among types of abuse on PTGI scores. The means among types of abuse are approximately equal except multiple abuses. The results are there is no difference in the level of post traumatic growth in relation to types of abuse. Previous researches showed that there is there is no difference in the level of post traumatic growth in relation to types of abuse (Riley, 2013).

Present study aimed to find out level of PTG. Results showed that males showed high level of PTG as compared to females, while in subscales the significant difference is found on 'spiritual change' between these two groups. Victims of natural disaster showed higher scores on PTGI, RTO and SC as compared to manmade disaster. On the level of subscales; in abuse victims' females have high scores on SC, males on AOL but non-significant difference on PTGI while in the victims of Bomb blast, flood and earthquake males showed significantly high scores on PTGI and its subscales as compared to females except non-significant difference between males and females on SC. While comparing four trauma groups, it was found that on PTGI, earthquake has higher mean as compared to Bomb blast, blast has higher means as compared to flood, flood has higher mean as compared to the abuse sample.

\section{Conclusion}

The current study focused upon the process of post traumatic growth $h$ in the victims of manmade and natural disaster by mixed design. In this regard, quantitative part of study depicted following conclusions: 
- Posttraumatic growth (PTG) is found in the victims of man-made disaster (i.e, bomb blast \& Abuse) and natural disaster (Earthquake \& Flood).

- Post traumatic growth is found more in the males than females, while in subscales the significant difference is found on 'spiritual change' between these two groups

- Level of PTG is found high in victims of natural disaster as compared to manmade disaster.

- There is no significant difference in the personal strength of victims of manmade disaster and natural disaster.

- There is non statistically significant means differences between married and unmarried sample. Both groups have approximately same score on PTGI.

- Less educated more likely to support natural disaster and educated respondents are more likely support to man-made disaster

- Level of Post traumatic growth increases with passage of Time.

- Level of post traumatic growth has not significant relationship with types of abuse.

- In the victims of Abuse, females have high scores on Spiritual Change, males on Appreciation of life as compared to males.

- The male victims of Bomb blast, flood and earthquake showed significantly high scores on PTGI.

- There is no gender difference in the abuse victims regarding spiritual change.

- Victims of Earthquake has higher level of PTG as compared to Bomb blast, blast has higher level of growth as compared to Flood victims, where as flood victims showed higher level of growth as compared to Abuse sample.

- Earthquake victims showed highest level of growth among all four sub categories of trauma under study.

- Level of growth increases with the passage of time.

\section{Implications of the Study}

- The present study is a first step to overcome the lack of comparative studies on post traumatic growth because still there is no study in the previous literature in which the process of post traumatic growth is intended to find 
out both in man-made disasters and natural disasters as well at a time. The present study will fill the gap of knowledge.

- There are very few researches conducted in Pakistan in the area of PTG so the present study is helpful to approach the Pakistani culture and its religion with the perspective of Post traumatic growth. The present study explains factors helpful in trauma victims to grow either they are suffering from manmade disaster or natural disaster.

- Finding out the post traumatic growth will be beneficial for therapists to help their clients identify and maximize the positive impacts that adverse life experiences may have had on them.

- The findings of this study can be incorporated into existing impact of traumas and trauma treatments.

- In this way, the present study would be helpful for planning an intervention for trauma sufferers within the context of Pakistani culture.

- Process of posttraumatic growth evolved out of the findings of the present study will be helpful for the Governmental and non-governmental organizations (NGO's) who are working for the rehabilitation of trauma victims of man-made and natural disasters. In short, the findings of the present study will be helpful for rescue workers, health professionals, rehabilitation service providers, direct or indirect informants of trauma who has either directly faced the trauma or just heard or seen such disaster through media. The readers of this study can get benefit from findings of the study if they have faced any type of trauma themselves or got disturbed due to indirect trauma exposure. 


\section{References}

American Psychiatric Association. (2013). Diagnostic and statistical manual of mental disorders (5th ed.). Washington, DC: Author.

Aslam, N., \& Kamal, A. (2015). Coping Strategies as a Predictors of Psychological Distress and Post Traumatic Growth among Flood Affected Individuals, Journal of Alcohol Drug Depend, 3:1.

Breslau, N., Davis, G. C., Andreski, P. \& Peterson, E. (1991). Traumatic events and Posttraumatic stress disorder in an urban population of young adults. Archives of General Psychiatry, 48(3), 16-22.

Briere, J. (2004). Psychological assessment of adult posttraumatic states: Phenomenology, diagnosis, and measurement (2nd ed.). Washington, DC: American Psychological Association.

Breslau, N. (2009). The epidemiology of trauma, PTSD, and other post trauma disorders. Trauma Violence Abuse, 10(3), 198-210.

Blix, I., Hansen, M., Birkeland, M., Nissen, A., \& Heir, T. (2013). Posttraumatic growth, posttraumatic stress and psychological adjustment in the aftermath of the 2011 Oslobombing attack. Health and Quality of Life Outcomes, 11(1), 160.

Bellizzi, K.M., Blank, T.O. (2006). Predicting posttraumatic growth in breast cancer survivors. Health Psychology 25 (1), 47-56.

Blore, D. C., Farrell, D., \& Clifford, C. (2008). The experience of post traumatic growth amongst road traffic accidents victims who have completed EMDR treatment: A status report on research. Poster presented at the 9th EMDR Europe Association Conference, London, England.

Bower, J.E., Meyerowitz, B.E., Desmond, K.A., Bernaards, C.A., Rowland, J.H., Ganz, P.A. (2005). Perceptions of positive meaning and vulnerability following breast cancer: predictors and outcomes among long-term breast cancer survivors. Annals of Behavioral Medicine 29 (3), 236-245.

Calhoun, L. G., Tedeschi, R. G., Cann, A., \& Hanks, E. (2010). Positive outcomes following bereavement: Paths to posttraumatic growth. 125-143.

Cann, A., Calhoun, L.G., Tedeschi, R.G., \&Solomon,D. T. (2010). Posttraumatic growth and depreciationas independent experiences and predictors of wellbeing. Journal of Loss and Trauma, 15, 151-166.doi:10.1080/15325020903375826

Cordova, M.J., Giese-Davis, J., Golant, M., Kronenwetter, C., Chang, V., Spiegel, D. (2007). Breast cancer as trauma: posttraumatic stress and posttraumatic growth. Journal of Clinical Psychology in Medical Settings 14 (4), 308-319 
Dannefer, D \& Philipson, C. (2010). The SAGE Handbook of Social Gerontology. Thousand Oaks: California: The Sage Publication.

Danieli, Y., Brom, D., \& Sills, J. (2005). The trauma of terrorism: contextual considerations. Journal of Aggression, Maltreatment and Trauma, 9(1), 1-17

Devine, K., Knight, B. R., Loiselle, K. A., Fenton, N., \& Blount, R. (2010). Posttraumatic Growth in Young Adults Who Experienced Serious Childhood Illness: A Mixed-Methods Approach. Journal of clinical psychology in medical settings. 17. 340-8. 10.1007/s10880-010-9210-7.

Economic Research \& Consulting (2016) Natural catastrophes and man-made disasters in 2015: Asia suffers substantial losses. Switzerland: Swiss Re Ltd

EME-DAT (2012). The International Disaster Database. Centre for Research on the Epidemiology of Disasters (CRED). Pakistan Country Profile - Natural Disasters for the period 1900 to 2012 http://www.emdat.be/result-country-profile. Accessed 25 December 2011.

Human Rights Commission of Pakistan (2018). The State of Pakistan in 2017. Published by Human Rights Commission of Pakistan. New Garden Town, Lahore.

Inter-Agency Standing Committee, Protecting Persons affected by Natural Disasters: IASC Operational Guidelines on Human Rights and Natural Disasters, Washington, DC: Brookings-Bern Project on Internal Displacement, June 2006.

Jia, X., Liu, X., Ying, L., \& Lin, C. (2017). Longitudinal Relationships between Social Support and Posttraumatic Growth among Adolescent Survivors of the Wenchuan $\quad$ Earthquake. Frontiers in Psychology, 8, 1275. http://doi.org/10.3389/fpsyg.2017.01275

Kilmer, R. P., \&Gil-Rivas, V. (2008). "Posttraumatic growth in youth following disasters." The Prevention Researcher,15(3), 18-20.

Kiran, M., Rana, M.H., and Azhar, M. (2010). Posttraumatic Growth Amongst Survivors Of A Suicide Bombing Attack In Northern Pakistan. Journal of Pakistan PsychiatricSociety, 7(1), 29

Kessler, R. C., Sonnega, A., Bromet, E., Hughes, M., \& Nelson, C. B. (1995). Posttraumatic stress disorder in the National Comorbidity Survey. Archives of General Psychiatry, 52, 1048-1060.

Kilmer ,R. P., Gil-Rivas, V. (2010). Exploring posttraumatic growth in children impacted by Hurricane Katrina: correlates of the phenomenon and 
developmental considerations. Child Dev. 81, 1211-1227. 10.1111/j.14678624.2010.01463.x

Kilic, C., Magruder, K.M., \&Koryurek, M. M. (2015). Does trauma type relate to posttraumatic growth after war? A pilot study of young Iraqi war survivors living in Turkey. Transcultural Psychiatry. 53(1). 110-123.

Kotin, E. (2018). The relationship between posttraumatic growth and body image among adult females who experienced childhood sexual abuse (Order No. 10824329). Available from ProQuest Dissertations \& Theses Global. (2050158439). R

Koutrouli, N., Anagnostopoulos, F., Potamianos, G., (2012). Posttraumatic stress disorder and posttraumatic growth in breast cancer patients: a systematic review. Women $\mathcal{E}$ Health 52 (5), 503-516.

Kucukkaya, P.G., (2010). An exploratory study of positive life changes in Turkish women diagnosed with breast cancer. European Journal of Oncology Nursing 14 (2), 166-173.

Lancaster, S,. L. Melka, S. E. \& Rodriguez, B. F. (2009). An examination of the differential effects of traumatic events and life stressors. Journal of Anxiety Disorders, 23, 711-717.

Laufer, A., \& Solomon, Z. (2006). Posttraumatic symptoms and posttraumatic growth among Israeli youth exposed to terror incidents. Journal of Social and Clinical Psychology, 25(4), 429-447.

Linley, P.A. and Joseph, S. (2004). Positive Change Following Trauma and Adversity: A Review. Journal of Traumatic Stress, 17, 11-21

Linley, P., Joseph, S., Cooper, R., Harris, S., \& Meyer, C. (2003). Positive and negative changes following vicarious exposure to the September 11 terrorist attacks. Journal of Traumatic Stress, 16(5), 481-485.

McCormack, L., \& McKellar, L. (2015). Adaptive growth following terrorism: Vigilance and anger as facilitators of posttraumatic growth in the aftermath of the Bali bombings. Traumatology 21(2), 71-81.

McMillen, J. C., Smith, E. M., \& Fisher, R. H. (1997). Perceived benefit and mental health after three types of disaster. Journal of Consulting and Clinical Psychology, 65(5), 733-739. http://dx.doi.org/10.1037/0022-006X.65.5.733

Milam, J., Ritt-Olson, A., Tan, S., Unger, J., \&Nezami, E. (2005). The September 11th 2001 , terrorist attacks and reports of posttraumatic growth among a multi-ethnic sample ofadolescents. Traumatology, 11(4), 233. 
Milam, J.E. (2006). Posttraumatic growth and HIV disease progression. Journal of Consulting and Clinical Psychology, 74, 817 - 827.

Morrill, E., Brewer, N., O'Neill, S., Lillie, S., Claire, D.E., Carey, L. A., \&Rimer, B.K.(2008). The interaction of post-traumatic growth and posttraumatic stress symptoms in predicting depressive symptoms and quality of life. PsychoOncology. 17:948-953.

Mosher, C. E., Danoff-Burg, S., \&Brunker, B. (2006). Post-traumatic growth and psychosocial adjustment of daughters of breast cancer survivors. Oncology Nursing Forum, 33(3), 543-551.

National Disaster Management Authority (NDMA). Annual Report (2011), National Disaster Management Authority Government of Pakistan.

Riaz, N., Malik, S., \& Nawaz, S. (2015). Well-being and post-traumatic stress disorder due to natural and man-made disasters on adults. Pakistan Journal of Medical Research. 54. 25-28.

Ouimette, P., \& Brown, P. J. (2003). Trauma and substance abuse: Causes, consequences, and treatment of comorbid disorders. Washington, DC: American Psychological Association

Pakistan Anti-Terrorism (Amendment) Ordinance 1999, promulgated by President RafiqTarar on April 29,1999 http://www.satp.org/satporgtp/countries/pakistan/document/actsandordine nces/anti_terrorism.htm

Polusny, M. A., \&Follette, V. M. (1995). Long-term correlates of child sexual abuse: Theory and review of the empirical literature. Applied \& Preventive Psychology, 4, 143-166.

Saghir, S \&Rukhsana, K. (2010). Posttraumatic Growth and marital Satisfaction after Breast Cancer: Patient Spouse Perspective. Pakistan Journal of Social and Clinical Psychology, 8(1).

Sears, S.R., Stanton, A.L., Danoff-Burg, S., 2003. The yellow brick road and the emerald city: benefit finding, positive reappraisal coping and posttraumatic growth in women with early-stage breast cancer. Health Psychology 22 (5), 487497.

Siqveland, J., Hafstad, G. S \&Tedeschi, R. G (2012) Posttraumatic Growth in Parents After a Natural Disaster, Journal of Loss and Trauma, 17(6), 536544, DOI: 10.1080/15325024.2012.678778 
Shakespeare-Finch, J., \& Armstrong, D. (2010). Trauma type and posttrauma outcomes: Differences between survivors of motor vehicle accidents, sexual assault, and bereavement. Journal of Loss and Trauma, 15, 69-82.

Shabib, H. S., Luqman, S., \& Roger, P. M. (2015.) Causes and Incentives for Terrorism in Pakistan, Journal of Applied Security Research, 10(2), 181-206,

Shultz, J.M., Neria. Y., \&Espinel, J. (2013). Psychological impacts of Natural Disasters. Research Gate. http://www.reserachgate.net/pbulication/23702011

Staff. "What is a disaster?". www.ifrc.org. International Federation of Red Cross and Red Crescent Societies. Retrieved 21 June 2017.

Stanton A., Bower J., Low C. (2006). Posttraumatic growth after cancer. In Calhoun L. G., Tedeschi R. G., editors. (Eds.), Handbook of posttraumatic growth: Research and practice (pp. 138-175). Mahwah, NJ: Erlbaum.

Subandi. M.A., Achmad. T., Kurniati. H., \&Febri. R. (2014). Spirituality, gratitude, hope and post-traumatic growth among the survivors of the 2010 eruption of Mount Merapi in Java, Indonesia. Australasian Journal of Disaster and Trauma Studies.18(1).

Taku, K., Cann, A., Calhoun, L., \&Tedeschi, R. (2008). The factor structure of the Posttraumatic Growth Inventory: A comparison of five models using confirmatory factor analysis. Journal of Traumatic Stress, 21(2), 158-164.

Tedeshi, R.G., \& Calhoun, L.G. (2004). Posttraumatic Growth: Conceptual Foundation and Empirical Evidence. Philadelphia, PA: Lawrence Erlbaum Associates.

Tedeschi, R.G., \& Calhoun, L.G. (1995). Trauma and Transformation: Growing in the Aftermath of Suffering. Thousand Oaks, CA: Sage

Tedeshi, R.G., \& Calhoun, L.G. (1996). The Posttraumatic Growth Inventory: Measuring the Positive Legacy of Trauma. Journal of Traumatic Stress, 9. 455-471.

Tedeschi, R. G., \& Calhoun, L. (1996). The Posttraumatic Growth Inventory: Measuring the positive legacy of trauma. Journal of Traumatic Stress, 9, 455- 471.

Tedeschi, R. G., \& Calhoun, L. (2004). Posttraumatic growth: Conceptual foundations and empirical evidence. Psychological Inquiry, 15(1), 1-18.

Tedeschi,R. G., \& Calhoun, L. (1999). Violence transformed: Posttraumatic growth in survivors and their societies, Aggression and Violent Behavior, 4 (1999), pp. 319341, 10.1016/S1359-1789(98)00005-6 
Tedeschi, R. G. \& Calhoun, L. G. (2004). Posttraumatic growth: Conceptual foundations and empirical evidence, Psychological Inquiry, 15 (2004), pp. 118, 10.1207/s15327965pli1501_01

Tylor, S. E., Wood, J. V., \&Lichtman, R.R. (1983). It could be worse: Selective evaluation as a response to victimization. Journal of Social Issues, 39, 19-40.

Wang, Y., Wang. H., Wang, Z., Xie, H., Shi, J., \& Zhao, X. (2015). The process of posttraumatic growth in individuals with traumatic spinal cord injury in Mainland China: An interpretative phenomenological analysis. Journal of Health Psychology. 22(5). 637 - 649

Wang, M ., Liu, J., Wang, H., Chen, J., Li, Y.(2014).Posttraumatic growth and associated socio-demographic and clinical factors in Chinese breast cancer survivors, European Journal of Oncology Nursing, 18(5). 478-483.

Widows M. R., Jacobsen, P. B., Booth-Jones M., Fields, K. K. (2005). Predictors of posttraumatic growth following bone marrow. Health Psychology, 24, 266-273. doi:10.1037/0278-6133.24.3.266

Wu X., Zhou X., Chen J., Zeng M., Tian Y. (2016). The relationship among social support, deliberate rumination and posttraumatic growth: a longitudinal study of adolescents after Wenchuan earthquake. Journal of Psychological Sciences. 39, 735-740. 10.16719/j.cnki.1671-6981.20160333

Yi, Jaehee., Zebrack, B., Kim, M. A., Cousino, M. (2015). Post traumatic Growth Outcomes and their Correlates among young adult survivors of Childhood cancer. Journal Pediatric Psychology, 40(9): 981-991

Zhou, X., Wu, X., Fu,F., \& An, Y. (2015). Core belief challenge and rumination as predictors of PTSD and PTG among adolescent survivors of the Wenchuan earthquake. Psychological Trauma: Theory, Research, Practice, and Policy, 7(4), 391397.

Zhou, X., Wu, X., \& Zhen, R. (2017). Understanding the relationship between social support and posttraumatic stress disorder/posttraumatic growth among adolescents after Ya'an earthquake: The role of emotion regulation. Psychological Trauma: Theory, Research, Practice, and Policy, 9(2), 214-221. 